\title{
Background electromagnetic noise characterization: the role of external and internal Earth sources
}

\author{
Antonio Meloni, Cesidio Bianchi ${ }^{\star}$, Giuliana Mele, Paolo Palangio
}

Istituto Nazionale di Geofisica e Vulcanologia, Rome, Italy

Article history
Received January 29, 2015; accepted June 9, 2015.
Subject classification:
Radio noise characterization, Ionosphere-magnetosphere, Background EM noise, Crustal/lithospheric EM sources.

\section{ABSTRACT}

The Earth is surrounded by the ionosphere and magnetosphere that can roughly be seen schematically as two concentric shells. These two composed and inhomogeneous structured shells around the Earth selectively affect electromagnetic (EM) waves propagation. Both ionosphere and magnetosphere interact also with particles and waves coming from external sources, generating electromagnetic phenomena that in turn might become sources of EM waves. Conversely, EM waves generated inside the ionosphere remain confined at various altitudes in this region, up to a socalled critical frequency limit, depending on frequency, EM waves can escape out of the ionosphere and magnetosphere or get through. The EM waves generated inside the magnetospheric cavity mainly originate as a result of the electrical activity in the atmosphere. It is well known that also man-made sources, now widely spread on Earth, are a fundamental source of EM waves; however, excluding certain frequencies employed in power distribution and communication, man-made noise can be dominant only at local scale, near their source. According to recent studies, EM waves are also generated in the Earth's lithosphere; these waves were sometimes associated with earthquake activity showing, on the Earth's surface, intensities that are generally orders of magnitude below the background EM noise. In this review paper, we illustrate EM waves of natural origin and discuss their characterization in order to try discriminate those of lithospheric origin detectable at or near the Earth's surface.

\section{Introduction}

The electromagnetic (EM) spectrum is subdivided into regions, according to wavelength (Table 1). The Earth's atmosphere prevents most of the electromagnetic radiation coming from outer space from reaching the Earth's surface; in fact, only portions of radio and visible light reach the ground.

The natural electromagnetic background noise in the Earth's environment originates from different phenomena that involve both Earth's external and internal sources and their possible interaction with the ionospheric and magnetospheric cavities. External sources bring EM radiations inside the magnetospheric cavity but they can also be generated inside the cavity, for example by energetic particles acting as forcing mechanisms that perturb and modify the ionospheric and magnetospheric configuration. The EM Power Spectral Density (PSD) at the Earth's surface was deeply studied and reported since the first extensive measurements were available, as discussed for example by Lanzerotti [1978] and Lanzerotti et al. [1990]. The most intensive near Earth's sources are associated with the atmospheric electrical activity, while the external sources mainly originate on the Sun. Relevant information about the external EM noise can be found in the CCIR/ITU (Comité Consultatif International pour la Radio; now also International Telecommunication Union) Radiocommunication Sector (ITU-R) reports, published in 1964, 1988, and 1990 [CCIR/ITU 1960, 1988, 1990], as well as in Davies [1990], Helliwell [2006], and Bianchi and Meloni [2007].

Sudden fluxes of particles that enter the magnetosphere generate magneto-hydro-dynamic (MHD) waves and other relevant phenomena, especially in the polar regions (e.g., auroral displays, magnetic substorms, Polar Caps Absorption) and also wave-particle interactions (whistlers, chorus, hiss). According to Lan-zerotti et al. [1990], PSD varies of about 16 orders of magnitude in the frequency band $10^{-5}-10^{5}$ $\mathrm{Hz}$, with values ranging from $\approx 10^{-1}$ to $10^{-17} \mathrm{~W} \mathrm{~m}^{-2}$ $\mathrm{Hz}^{-1}$. For frequencies up to the $\mathrm{GHz}$, the PSD falls to $\approx 10^{-21} \mathrm{~W} \mathrm{~m}^{-2} \mathrm{~Hz}^{-1}$. The spectrum of the EM perturbations inside the ionosphere and magnetosphere cavities is mostly studied for the ULF (Ultra Low Frequencies) up to the HF (High Frequency) bands. Highest frequencies will not be considered in this paper since, starting from $\mathrm{HF}$ onwards, i.e. corresponding to waves able to escape the ionosphere, the background noise decreases accordingly. In Table 1 acronyms, frequency, wavelength and PSD approxi- 


\begin{tabular}{|c|c|c|c|c|}
\hline Sources of natural EM radio noise & Frequency & $\begin{array}{l}\text { Wavelength } \\
\qquad(\mathrm{m})\end{array}$ & $\begin{array}{l}\text { Spectral power } \\
\left(\mathrm{W} \mathrm{m}^{-2} \mathrm{~Hz}^{-1}\right)\end{array}$ & $\begin{array}{l}\text { Physical } \\
\text { environment }\end{array}$ \\
\hline $\begin{array}{l}\text { resonance in the magnetospheric cavity, } \\
\text { interaction with particles of solar origin and } \\
\text { radiative pressure with the magnetosphere }\end{array}$ & $\begin{array}{c}\text { ULF } \\
0.1 \div 3,000 \mathrm{mHz}\end{array}$ & $3 \cdot 10^{11} \div 10^{8}$ & $10^{-1} \div 10^{-10}$ & magnetosphere \\
\hline resonance in the ionospheric cavity & $\begin{array}{c}\text { ELF } \\
3 \div 3,000 \mathrm{~Hz}\end{array}$ & $10^{8} \div 10^{5}$ & $10^{-10} \div 10^{-12}$ & ionosphere \\
\hline $\begin{array}{l}\text { propagation in the ionospheric cavity } \\
\text { of the radiating atmospheric discharge }\end{array}$ & $\begin{array}{c}\text { VLF } \\
3 \div 30 \mathrm{kHz}\end{array}$ & $10^{5} \div 10^{4}$ & $10^{-12} \div 10^{-14}$ & ionosphere \\
\hline atmospheric noise & $\begin{array}{c}\text { LF-MF-HF } \\
30 \mathrm{kHz} \div 30 \mathrm{MHz}\end{array}$ & $10^{4} \div 10^{2}$ & $10^{-14} \div 10^{-17}$ & ionosphere \\
\hline
\end{tabular}

Table 1. Main physical characteristics of the natural EM radio noise sources in the magnetosphere and ionosphere.

mate values of the natural radio noise sources in the magnetosphere and ionosphere, are reported. As briefly reported above, the background EM noise becomes less important at higher frequency while the cosmic noise is prevalent starting from VHF-UHF frequency band. At lower frequency a primary source of noise is the interaction between particles and waves coming from outer space and the magnetosphere, while a secondary source originates inside the ionospheric cavity: in this case atmospheric lightning discharges produce several remarkable phenomena such as sferics, tweeks and so on [e.g., Wait 1982, Helliwell 2006, Bianchi and Meloni 2007, and references therein]. Over the range $\approx 10^{-4}$ to $\approx 10^{4} \mathrm{~Hz}$ the amplitude spectra $(\mathrm{fT} / \sqrt{\mathrm{Hz}})$ fall between the two straight lines $\mathrm{f}^{-1.5}$ and $\mathrm{f}^{-1}$ with an average half line slope that rolls off as $\mathrm{f}^{-1.25}$ (Figure 1). As a natural trend, the

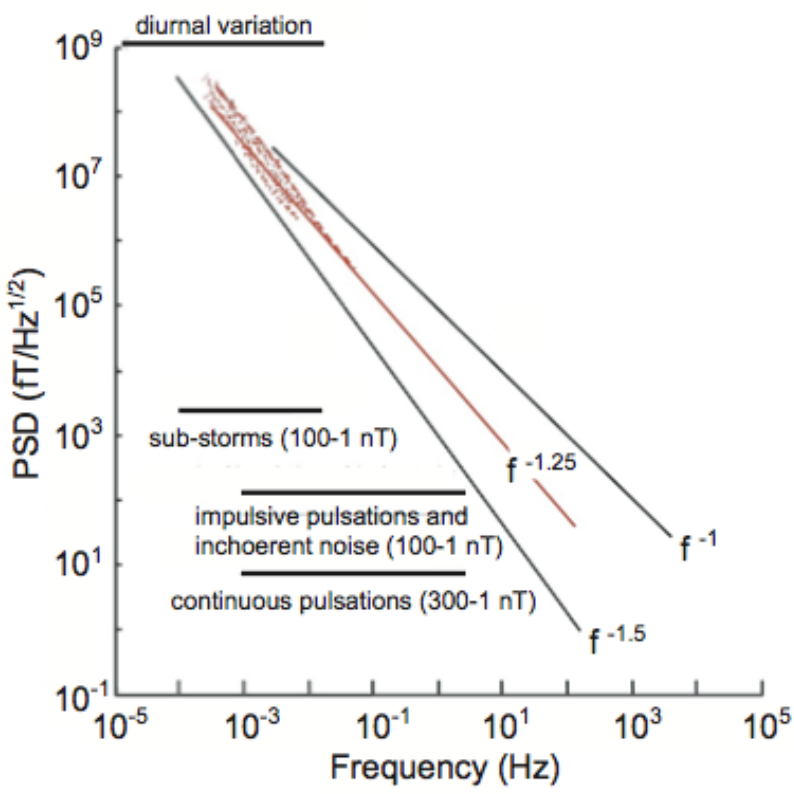

Figure 1. EM natural noise PSD. In the frequency interval from $10^{-4}$ to $10^{4} \mathrm{~Hz}$, the noise falls between the two straight lines trending as $\mathrm{f}^{-1}$ and $\mathrm{f}^{-1.5}$ (redrawn after Lanzerotti et al. [1990]). spectral density decreases considerably from lower to higher frequency, since contributions to background noise from sources internal to the cavities are less important and cosmic noise becomes prevalent up to the millimetric wavelength. The $\mathrm{f}^{-1}$ decay is a natural trend, being a constant when considering a confined environment [Füllekrug and Fraser-Smith 2011].

The purpose of this work is to describe the EM background noise in the Earth's environment and to compare the natural external signals with the internal Earth's crust, or more generally lithospheric, sources. These are supposed to be weaker and local and to have peculiar characteristics that can be used to discriminate the internal from the external contributions (see a review by Hayakawa and Hobara [2010]). EM emissions radiated from the lithosphere were at times related to earthquakes occurrence. In particular, many authors have hypothesized that EM waves can be generated at the hypocenter during the earthquake or its preparation phase [e.g., Hayakawa et al. 1996, Johnston 2002, Teysseire and Ernst 2002, Uyeda et al. 2009]; reported EM phenomena take place in a wide frequency range [see for example: Hayakawa and Fujinawa 1994, Hayakawa and Molchanov 2002]. Some reported ionospheric phenomena, were related to earthquake occurrence $[\mathrm{Pu}$ linets et al. 2007], but were criticized. In fact Thomas et al. [2012] had reproduced the same time series results, in which the authors identified an anomalous signal, and found it was normal solar and geomagnetic activity that were, in their opinion, unrelated to the earthquake.

In the following, the most relevant sources of natural EM waves, in the various frequency ranges, will be treated separately.

\section{Background noise in the ULF range}

Geomagnetic pulsations, also called micropulsations (or simply pulsations) are the ground signature of ultra low frequency (ULF) hydromagnetic waves prop- 
agating in the Earth's magnetosphere [Anderson 1993, 1994]. Their period varies from less than $1 \mathrm{~s}$ to $10 \mathrm{~min}$, while their amplitude varies from tens to hundreds nT, increasing with increasing period and magnetic latitude. Traditionally, micropulsations are classified as continuous (Pc) and irregular (Pi) as reported in Table 2. Most of the ULF waves detected at the Earth's surface originate outside the magnetosphere [Yumoto 1988]. The solar wind, the magnetospheric foreshock, the magnetospheric bow shock, and the magnetopause, are sources of ULF waves. Many of these waves pass through the magnetopause and propagate through the magnetosphere interacting with waveguides, magnetic field lines and the ionosphere generating the pulsations detected at the Earth's surface.

Externally generated ULF waves detected at the ground level are not identical to waves that enter the magnetosphere through the solar wind, since their energy is transformed and amplified inside the magnetosphere [see for example McPherron 1991]. Schematically, regular pulsations from Pc3 to Pc5 are due to the so called Kelvin-Helmholtz instability generated at the magnetopause by the differential flow of the solar wind on either side of the magnetosphere. Another mechanism of pulsations generation, mainly in the bands Pc3-Pc4, is given by the penetration of waves generated upstream from the bow shock region, called 'upstream waves' into the magnetosphere. Pc1 and Pc2 have periods comparable with cyclotronic resonances in the magnetosphere and are associated with the magnetospheric plasma, in particular drift of protons and heavier ions.

Pulsations amplitude is normally not larger than a few $\mathrm{nT}$ in the Pc1 and Pc2 range and a few tens of $\mathrm{nT}$ at longer periods; in exceptional cases pulsations can reach very large amplitudes (100 nT and more). Short period pulsations Pc1, Pc2 and Pi1 are travelling waves, while long period pulsations are mainly standing waves inside the magnetospheric cavity. The same mechanism can be observed in the ionospheric cavity for low frequency longitudinal and transversal standing waves. The short period pulsations are related to the Kp magnetic activity index; they show both frequency and amplitude modulation and are more sporadic than the longer period pulsations [Kangas et al. 1998].

The understanding of the pulsation generation mechanisms requires a detailed knowledge of the magnetosphere structure and dynamics that is beyond the purpose of this work. Long period pulsations (Pc5 and Pc4) are the magnetic signatures of plasma waves with wavelengths comparable to the magnetospheric size. These large-amplitude (up to hundreds of nT), low-frequency continuous pulsations are much stronger in the auroral zone [Samson and Rostoker 1972]. In the vicinity of the resonance shell, a portion of the energy of these waves is transferred, through a coupling phenomenon, to Alfven oscillations and then to Pc5 and Pc4 pulsation standing waves [Kivelson et al. 1984, Surkov and Hayakawa 2008].

Continuous pulsations

\begin{tabular}{|c|c|c|c|c|c|}
\hline & Pc1 & Pc2 & Pc3 & Pc4 & Pc5 \\
\hline Period (s) & $0.2-5$ & $5-10$ & $10-45$ & $45-180$ & $150-600$ \\
\hline Frequency $(\mathrm{mHz})$ & $5,000-200$ & $200-100$ & $100-22$ & $22-7$ & $7-2$ \\
\hline Maximum intensity (nT) & 1 & 3 & 10 & $<300$ & 300 \\
\hline Source & $\begin{array}{l}\text { EM ion-cyclotron } \\
\text { instability } \\
\text { in the equatorial } \\
\text { magnetosphere }\end{array}$ & $\begin{array}{l}\text { EM ion-cyclotron } \\
\text { instability } \\
\text { in the equatorial } \\
\text { magnetosphere }\end{array}$ & $\begin{array}{c}\text { wave-particle } \\
\text { interaction } \\
\text { in the bow shock } \\
\text { region }\end{array}$ & $\begin{array}{l}\text { drift of protons } \\
\text { from the night side }\end{array}$ & $\begin{array}{l}\text { magnetopause } \\
\text { instability }\end{array}$ \\
\hline
\end{tabular}

\begin{tabular}{|c|c|c|c|}
\hline \multicolumn{3}{|c|}{ Impulsive pulsations } & \multirow{2}{*}{ Incoherent noise } \\
\hline & Pi1 & Pi2 & \\
\hline Period (s) & $1-40$ & $40-150$ & $1-1,000$ \\
\hline Frequency $(\mathrm{mHz})$ & $1,000-25$ & $25-2$ & $1,000-1$ \\
\hline Maximum intensity (nT) & 10 & 100 & - \\
\hline Source & $\begin{array}{c}\text { modulation } \\
\text { of charged particles }\end{array}$ & sub-storms & $\begin{array}{l}\text { ionospheric } \\
\text { electric currents }\end{array}$ \\
\hline
\end{tabular}

Table 2. IAGA classification and standard nomenclature of the most relevant continuous and impulsive pulsations in the ULF band. 


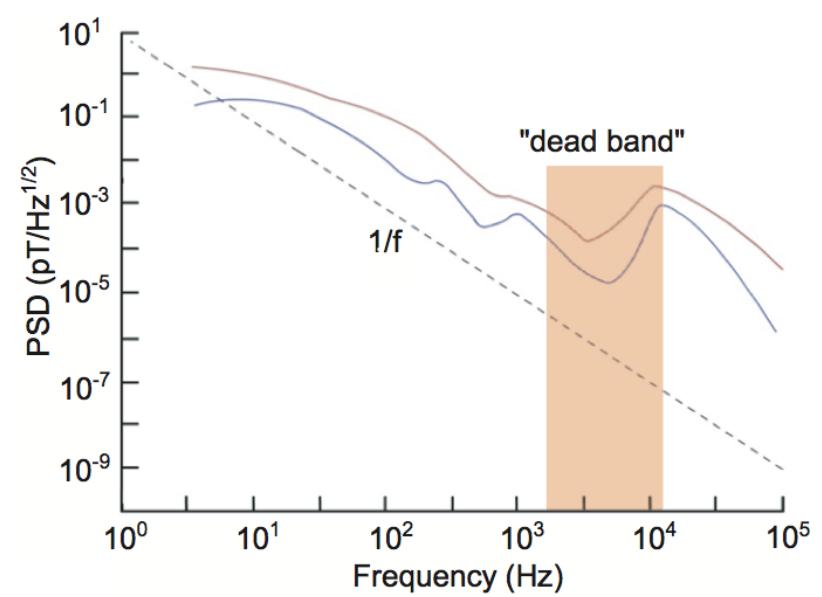

Figure 2. PSD of the ELF-VLF background mid-latitude noise. The blue and red lines indicate minima and maxima, respectively.

\section{Background noise in ELF-VLF range}

Broad-band ELF-VLF spectrum measurements made in typical low noise environments, show a uniform structure all over the Earth [Lanzerotti et al. 1990]; a more intense radio noise is present at high latitude in the frequency band between 0.5 and $1,500 \mathrm{~Hz}$, where so called polar hiss/chorus emissions can be relevant [Golden et al. 2009]. Typical background noise at mid latitude in the VLF-ELF band is reported in Figure 2 [Fraser-Smith 2007]. During daytime, the background noise is particularly attenuated in the frequency window 1-5 kHz [Garcia and Jones 2002]. This frequency interval is called "dead band" and is nearly coincident with the transversal resonances of the ionospheric cavity.

The EM noise background fills the space around the Earth interacting in a complex way with the magneto-ionosphere boundary shells at various altitudes and latitudes. The EM background noise due the superimposition of numerous sources distributed inside the two cavities [Meloni et al. 1992] is the result of all the existing phenomena, such as sferics, tweeks, whistlers and others [e.g., Wait 1982, Helliwell 2006, Bianchi and Meloni 2007], and of the complex interaction of the EM fields with the approximate reference surfaces delimiting the cavities. In general, as mentioned before, the largest the cavity volume, the lowest the resonant frequencies and the highest the intensity of the fields confined in the cavity.

The background noise in the ionospheric cavity is sustained by a range of 60-100 natural lightning electrical discharges per second, especially generated in the tropics, with a wide spectrum ranging from few $\mathrm{Hz}$ to hundreds of $\mathrm{MHz}$. This spectrum is strongly influenced by the ionospheric cavity shape and, as a result, only signals in the spectral windows ranging from about 8 to $45 \mathrm{~Hz}$, survive. These are the Schumann longitudinal resonances [Bliokh et al. 1980, Sentman 1987, Sentman and Fraser 1991] and related harmonics. All possible EM frequencies are given by the relation:

$$
f_{n}=\frac{c}{2 \pi a} \sqrt{(n(n+1)}
$$

where $a$ is the Earth's radius, $c$ is the velocity of light in vacuum and $n$ is any integer number. Moreover the conductive layer of the ionosphere, at about $100 \mathrm{~km}$ of height, gives the highest amplitude resonant frequency and related harmonics, not on a global scale, in the 900$5,000 \mathrm{~Hz}$ band (transversal resonances).

In the frequency band from 5 to $30 \mathrm{kHz}$, the dominant signals are the sferics (also called statics), that are frequently audible in the radio equipments, as well as the tweeks (dispersed sferics) are. Taking into consideration a single lightning discharge, the observed spectrum depends on the source-observer distance and is called source spectrum. The convolution of the source function with the cavity transfer function becomes more and more important at increasing distance. As a consequence the nearest observer detects a maximum intensity around $300 \mathrm{kHz}$, the farthest observer experiences a maximum intensity around $7 \mathrm{kHz}$.

Table 3 shows the main EM sources in the magnetosphere and ionosphere. In the frequency range from ELF/VLF to LF, the PSD varies roughly as the inverse squared frequency [Fraser-Smith 1995].

\section{Possible origin and mechanisms for internal Earth generated EM waves}

The description of the ionospheric and magnetospheric signals, in the frequency range from ULF to VLF, above presented, attains to a consolidated investigation field, following several decades of radio wave investigations. In the lasts decades several authors have reported on the existence of internally generated EM waves that are reported as weaker and local. Detection of EM waves of internal Earth origin is made with direct observation of electromagnetic emissions from the lithosphere. We should mention however that some authors also operate detecting signals originated in the lithosphere, indirectly. This is done investigating on the propagation anomaly of a pre-existing transmitter signal; the anomaly could be due to a mechanism of lithosphereatmosphere-ionosphere coupling [see: Uyeda et al. 2009, Haykawa and Hobara 2010, and references therein]. The characterization of EM waves generated by internal Earth sources, is done in terms of their range of frequency and amplitude, wave attenuation, crustal or subsoil mode of propagation, that allow to detect this kind of EM emission. Moreover the type of emitting process encompasses a range of uncertainty that is still domi- 
(a)

\author{
Magnetospheric sources \\ Free oscillations in the magnetospheric cavity \\ Resonance in the magnetospheric cavity \\ Magneto-hydrodynamic waves in the magnetospheric cavity \\ Resonance wave-particles (transversal and longitudinal) \\ Emission due to plasma instabilities
}

(b) Ionospheric sources

Emission due to ablation of meteorites

Sferics

Sprite, Blue Jet, Red Flash, Elves

Longitudinal resonance in the ionospheric cavity

Transversal resonance in the ionospheric cavity

Atmospheric gamma rays
$\mathrm{Hz}$
$3 \cdot 10^{-3}-10^{2}$
$0.1-10$
$10^{1}-2 \cdot 10^{4}$
$3 \cdot 10^{4}-2 \cdot 10^{4}$
$3 \cdot 10^{-3}-10^{5}$

Table 3. (a) Magnetospheric and (b) ionospheric EM sources.

nant in the achieved findings [Dea et al. 1993, Johnston 2002, Teysseire and Ernst 2002, Palangio et al. 2007].

All authors generally reported that rocks modification or fracture in the Earth's crust, could produce EM waves. The fracture in brittle materials, such as solid rocks, can be envisaged as the result of a series of different phases taking place prior to earthquakes, summarized in the so called dilatancy theory [Stuart 1974]. This theory is based on the idea that a rock, when stressed, begins to increase its volume or to dilate; this is caused by the opening of micro-cracks and fractures in the rock. This theory was revitalized several times for earthquake prediction, but also severely criticized [Geller et al. 1997]. The sequence of events is following: 1) accumulation of stress; 2) micro-fracturing; 3) dilatancy; 4) macroscopic rupture. This last rupture occurs with release of stress and emission of seismic waves. In the Earth's crust the first phase can last tens of years, centuries, or even more, and the stress can increase continuously or with intermittence. The macroscopic rupture of rocks consists in a fracturing at the microscopic scale, radiating elastic energy in a manner analogous to earthquakes [Scholz 1968, Kato et al. 1994].

When micro-fracturing occurs in certain rocks, it can cause piezoelectric effects that create packets of EM waves of different frequency capable of travelling significant distances through the Earth's crust before reaching the surface. This is one of the mechanisms that could account for generation of EM waves before earthquakes [Johnston 2002, and references therein]. Micro-fracturing occurs when a rock is roughly half a way towards its breaking point. Several laboratory experiments were undertaken to detect these waves in a controlled envi- ronment [e.g., Freund 2008, 2009].

The change in the rock size may lead to the uplift of ground surface or to a variation in the groundwater pressure and level. Bolt [1988] has shown that, as crustal rocks break up under the tectonic stress preceding an earthquake, the variation in the pore pressure inside the rock causes a temporary decrease of the seismic $P$ waves velocity. Unfortunately, the time interval between the P-wave velocity change and the earthquake, might last months or years; the greater the magnitude of the earthquake, the greater the lapse time. Much of earthquake predictions was based on the changes that the rocks undergo when they are subject to all these phases. Rocks change physically transmitting seismic waves at changing speeds, magnetic properties can be altered and electrical resistance will also vary. Famous example is the Guam earthquake with magnitude 8.0 occurred in 1993 [Hayakawa et al.1996]. Thomas et al. [2009] report however, that the anomalous magnetic noise identified by Fraser-Smith et al. is not related to the Loma Prieta earthquake but, according to their work, was an artifact of sensor-system malfunction. Also in the case of Guam 1993 earthquake Thomas et al. [2009] reported that the changes in polarization was part of normal global magnetic activity and unrelated to the earthquake. So the above mentioned results and their interpretation are still awaiting for confirmation.

For what concerns EM waves generation process, piezo-magnetism, but also other physical mechanisms, have been proposed to explain the appearance of magnetic waves prior to earthquakes. Other possible EM waves generation mechanisms include electro-kinetic [Fenoglio et al. 1995, Simpson and Taflove 2005] and 
magneto-hydrodynamic effects [Surkov and Pilipenko 2014], resulting from fluid circulation through the crust, stress-induced increase in local crustal electrical conductivity [Merzer and Klemperer 1997], micro-fracturing, thermal magnetization/demagnetization effects and so on [Johnston 2002, Uyeda et al. 2009].

Freund $[2008,2009]$ has suggested a semiconductor model of rocks to describe unipolar magnetic pulses, as several times was observed prior to earthquakes. The suggested mechanism is based on coupling a semiconductor drift-diffusion model to a magnetic field to describe the electromagnetic effects associated with electrical currents flowing within rocks [see also Scoville et al. 2014]. However for fluid saturated samples, according to Dahlgren et al. [2014], observation of significant electrical charge buildup is not expected during the observed slow stress accumulation prior to earthquakes, or during any slow precursory stress release that may occur in the region of earthquake nucleation.

\section{Characterization of internal Earth sources}

For what concerns the Earth's crust, or more generally the lithosphere, among the less known quantities, are the EM properties. Once the variability range of electrical conductivity $(\sigma)$ and electrical permittivity $(\varepsilon)$ is established, other features of the EM internal signals that enable to discriminate them from external sources, can be inferred within an acceptable level of accuracy. Except for frequency and intensity, other signal electromagnetic characteristics like velocity, propagation mode, polarization, impulsiveness, coherence and spectral content, strongly depend on the media electrical properties. Most of the published works deal with the ULF and ELF part of the electromagnetic spectrum. In fact, electromagnetic signals produced in the seismogenic layer (for example between 10 and 20 $\mathrm{km}$ of depth, Chiarabba et al. [2005]), that can reach the Earth's surface with little attenuation [Molchanov and Hayakawa 1995], fall in the ULF-ELF bands.

In this framework the most probable internal signals should have the following characteristics:

- frequency range $0.01-1,000 \mathrm{~Hz}$

- magnetic intensity range 1-100 fT

- depending on $\sigma$, the diffuse magnetic field velocity range $1,000-10,000 \mathrm{~km} / \mathrm{s}$

- polarization, depending on sources pattern and nature

- impulsiveness, following estimate of the probability density function

- coherence, depending on the extent of the source.

Sources can be magnetic, electric and hybrid, with the spectral content depending on the medium characteristics and the statistical behavior depending on the (a)

Mechanism of emission

Point source elemental dipole

Extended elemental dipole

Point source hybrid multipole

Extended hybrid multipole

(b) Spectral content and trend

Thermic (white)

Colored

Complex

(c)

Statistical behavior
Gaussian
Isotropic
Stationary
Impulsive sources
Homogeneous sources

Table 4. Some expected features of the EM wave internal sources.

emission mechanism. In Table 4 some of the expected features of the internal sources are listed.

Depending on distance, the EM fields emitted by a source, or scattered by a reflector, are always characterized by an inductive, so-called near field, and a propagating so-called far field. Here, 'near' and 'far', are referred with respect to: a distance $d$ from the source, the wavelength $\lambda$, the extent and the coherence of the source $D$ physical dimension. Through the above quantities, four spatial regions are defined: (2) reactive field region, (3) I Fresnel's region, (4) II Fresnel's region, and (5) Fraunhofer's region:

$$
\begin{gathered}
d<\frac{\lambda}{2 \pi} \\
\frac{\lambda}{2 \pi}<d<\frac{D^{2}}{4 \lambda} \\
\frac{D^{2}}{4 \lambda}<d<\frac{2 D^{2}}{\lambda} \\
d>\frac{2 D^{2}}{\lambda}
\end{gathered}
$$

The EM near field contains useful information on the nature of the source, but the way to resolve this matter can be rather complex. In the near field the signal's power falls as $r^{-5}$ with the distance $r$ from the source and there is no propagating field except for a small fraction that will sustain the far field. In the above defined condition (a) the $\mathrm{E} / \mathrm{H}$ ratio gives indication about the magnetic/electric nature of the source [Palangio et al. 2008]. In the regions (b), (c) and (d) the power falls as 
$r^{-4}, r^{-3}$ and $r^{-2}$ respectively, while the wave impedance is defined only in (d). These considerations are essential both for signal measurement purpose and analysis, in order to characterize the observed signal properties.

In the terrestrial environment quasi non radiating (QNR) magnetic sources, whose fields remain confined in the same volume of the source, are quite common. Typical examples are the toroidal sources e.g., dynamo in the Earth's core and in the ionosphere. These sources are generally complex, with toroidal components that are not observable far from the source, while the system energetic balance cannot be resolved by measurements made externally to the system. Only the sources poloidal components can be measured. Very extended sources, larger than the dominant observed signal wavelength, emit electric and magnetic fields whose space-time correlation length reflects coherence properties that depend on the nature of the emitting source (see general Geomagnetism textbooks, e.g.: Backus et al. [1996], Campbell [2001]).

\section{Conclusions}

In this paper, we started describing the terrestrial natural EM noise in the frequency band from $10^{-5}$ to $10^{5}$ $\mathrm{Hz}$. Sections 2 and 3 were devoted specifically to the main natural sources of EM waves in the ionospheric and magnetospheric cavities, in the frequency ranges from ULF to VLF. The following sections dealt with EM sources that could be of Earth's internal origin.

We have shown some typical characteristics of natural sources in the ionosphere and magnetosphere cavities and some of their relevant properties. We have shown that the EM natural background radio noise follows some general physical laws. For example the background noise generated externally to the Earth's surface, shows a PSD that follows a typical decreasing trend, as shown in Figures 1 and 2, exhibiting a repeating pattern that displays at every scale; this occurrence is typical of fractals, as it happens in many other natural phenomena.

We have not dealt here in detail with the EM manmade radio noise sources and their characteristics; we know however that this noise can be compared with natural noise, and that only in particular in the ELF band, the two contributions can be easily mixed up. Moreover in the past decades, the widespread EM field measurements eliminated some uncertainty concerning natural noise parameterization in terms of timespace-frequency.

Electromagnetic signals existing in the ionospheric and magnetospheric cavities are not observed only as primary fields but also as secondary. In fact they can penetrate the Earth and propagate at various depths with different attenuations depending on the frequency and on the electric characteristics of the media. This issue is dealt with in Magnetotelluric methods that try to characterize the internal Earth electrical conductivity by means of a combination of electric and magnetic measurements on the Earth's surface [Garcia and Jones 2002] and in some cases by means of magnetic field time variations transfer functions only [Egbert and Booker 1986]. These induced signals can also be reflected at the interfaces and interfere with the primary inducing signals. This leads to a representation of the distribution of electromagnetic fields in the time-space and frequency domain.

In case of possible lithospheric sources, the emitted signal's energy is not yet characterized and is reasonably dependent on the distance. While for ionospheric or magnetospheric sources, the emitted energy is better characterized. It has been reported also that the signal polarization, the ratio of magnetic vertical to horizontal component, is relatively small for the plasma waves coming from the ionosphere/magnetosphere, while this ratio is considerably enhanced, for lithospheric origin emissions. Moreover the signal impulsiveness can be important to discriminate the internal sources. In fact impulsiveness is a quality of internal sources while if observed in case of external sources, it should subsist at a large scale, if not worldwide. If a local array network, consisting of at least three stations can be used in the field, the so called 'direction finding' radio technique can be used to infer the signal internal origin. The operating method can be goniometric or gradiometric. In the Izu and Chiba peninsulas (Japan), by measuring the gradient of horizontal and vertical components of the magnetic field at different frequencies, Kopytenko et al. [2002] and Ismaguilov et al. [2002] have computed the azimuth of the incoming waves from the normal to the observed gradient, leading to an internal source. In case of internal Earth generated signals no significant correlation between EM signals and geomagnetic activity, expressed also with geomagnetic indices, should be found.

Possible relations of EM waves propagating in the ionospheric-magnetospheric cavity and earthquakes, as we have also mentioned before, cannot be excluded 'a priori'. We note however that the mechanism of lithosphere-atmosphere-ionosphere coupling, that should be relevant as the final goal of seismo-electromagnetics, still needs to be deeply investigated. As we have reported here the separation between the various external sources of EM signals and the Earth internal sources, is on the other hand the primary problem to be solved and many questions still remain unanswered on the separation of the two contributions. However some elements 
concerning the internal EM source are now considered important, for example the knowledge of electrical conductivity, permittivity, temperature, chemical composition of the crust and its layered structure, with possible travel paths, might play an important role in this research field. Moreover the EM probable frequency band for these phenomena should fall in the ULF-ELF bands. For this reason a detailed monitoring and knowledge of the background EM noise is still needed.

\section{References}

Anderson, B.J. (1993). Statistical studies of Pc 3-5 pulsations and their relevance for possible source mechanisms of ULF waves, Ann. Geophysicae, 11, 128-143.

Anderson, B.J. (1994). An overview of spacecraft observations of $10 \mathrm{~s}$ to $600 \mathrm{~s}$ period magnetic pulsations in the Earth's magnetosphere, In: M.J. Engebretson, K. Takahashi and M. Scholer Solar (eds.), Wind Sources of Magnetospheric Ultra-Low-Frequency Waves, AGU Geophysical Monograph, 81, 25-43.

Backus, G., R. Parker and C. Constable (1996). Foundations of geomagnetism. Cambridge University Press, Cambridge, 369 pp.

Bianchi, C., and A. Meloni (2007). Terrestrial natural and man-made electromagnetic noise: an outlook, Annals of Geophysics, 50 (3), 435-445.

Bliokh, P.V., A.P. Nikolaenko and Y.F. Filippov (1980). Schumann Resonances in the Earth-Ionosphere Cavity, Peter Peregrinus Ltd., London.

Bolt, B. (1988). Earthquakes, W.H. Freeman, 282 pp.

Campbell, W.H. (2001). Earth magnetism. A guided tour through magnetic fields. Harcourt Academic Press, San Diego, CA, USA, 151 pp.

CCIR/ITU (1964). World distribution and characteristics of atmospheric radio noise, Rep. 322, Int. Radio Consultative Comm., Int. Telecommun. Union, Geneva, Switzerland.

CCIR/ITU (1988). Characteristics and applications of atmospheric radio noise data, Rep. 322-3, Int. Radio Consultative Comm., Int. Telecommun. Union, Geneva, Switzerland.

CCIR/ITU (1990). Man-made radio noise, Rep. 258-5, Int. Radio Consultative Comm., Int. Telecommun. Union, Geneva, Switzerland.

Chiarabba, C., L. Jovane and R. Di Stefano (2005). A new view of Italian seismicity using 20 years of instrumental recordings, Tectonophysics, 395 (3-4), 251-268; doi:10.1016/j.tecto.2004.09.013.

Dahlgren, R.P., M.J.S. Johnston, V.C. Vanderbilt and R.N. Nakaba (2014). Comparison of the Stress Stimulated Current of Dry and Fluid Saturated Gabbro Samples, B. Seismol. Soc. Am., 104, 2662-2672; doi:10.
$1785 / 0120140144$.

Davies, K. (1990). Ionospheric Radio (Peter Peregrinus Ltd., London, U.K.). IEE Electromagnetic Waves Ser. 31, 580 pp.

Dea, J.Y., P.M. Hansen and W.M. Boerner (1993). Longterm ELF background noise measurements, the existence of window regions, and applications to earthquake precursor emission studies. Phys. Earth Planet. Interior, 77, 109-125.

Egbert, G.D., and J.R. Booker (1986). Robust estimation of geomagnetic transfer functions, Geophys. J. R. Astron. Soc., 87, 173-194.

Fenoglio, M.A., M.J.S. Johnston and J.D. Byerlee (1995). Magnetic and electric fields associated with changes in high pore pressure in fault zones: application to the Loma Prieta earthquake, J. Geophys. Res., 100 (B7), 12951-12958.

Fraser-Smith, A.C. (1995). Low-frequency radio noise, In: H. Volland (ed.), Handbook of Atmospheric Electrodynamics, 1, 297-310, CRC Press.

Fraser-Smith, A.C. (2007). The effective antenna noise figure $\mathrm{Fa}$ for a vertical loop antenna and its application to extremely low frequency/very low frequency atmospheric noise, Radio Sci., 42, RS4026; doi:10.10 29/2005RS003387.

Freund, F.T. (2008). Earthquake probabilities and preearthquake signals, Current Sci., 94, 1-2.

Freund, F.T. (2009). Stress-activated positive hole charge carriers in rocks and the generation of pre-earthquake signals, In: M. Hayakawa (ed.), Electromagnetic Phenomena Associated with Earthquakes, Research Signpost, India, 41-96; ISBN 978-81-7895-297-0.

Füllekrug, M., and A.C. Fraser-Smith (2011). The Earth's electromagnetic environment, Geophys. Res. Lett., 38, L21807; doi:10.1029/2011GL049572.

Garcia, X., and A.G. Jones (2002). Atmospheric sources for audio-magnetotelluric (AMT) sounding, Geophysics, 67 (2), 448-458; doi:10.1190/1.1468604.

Geller, R.J., D.D. Jackson, Y.Y. Kagan and F. Mulargia (1997) Earthquakes Cannot Be Predicted, Science, 275 (14), 1616-1617.

Golden, D.I., M. Spasojevic and U.S. Inan (2009). Diurnal dependence of ELF/VLF hiss and its relation to chorus at L=2.4, J. Geophys. Res., 114, A05212; doi:10.1029/2008ja013946.

Hayakawa, M., and Y. Fujinawa (1994). Electromagnetic Phenomena Related to Earthquake Prediction, Terra Scientific, Tokyo.

Hayakawa, M., R. Kawate, O.A. Molchanov and K. Yumoto (1996). Results of ultra-low frequency magnetic field measurements during the Guam earthquake of 8 August 1993, Geophys. Res. Lett., 23, 241-244.

Hayakawa, M., and O.A. Molchanov (2002). Seismo Elec- 
tromagnetics: Lithosphere-atmosphere-ionosphere coupling, Terra Scientific, Tokyo.

Hayakawa, M., and Y. Hobara (2010) Current status of seismo-electromagnetics for short-term earthquake prediction, Geomatics, Natural Hazards and Risk, $1 / 2,115-155$.

Helliwell, R.A. (2006). Whistlers and Related Ionospheric Phenomena, Dover Publications, Inc., ISBN 0-486-44572-0; originally published by Stanford University Press, Stanford, California, 1965.

Ismaguilov, V.S., Y.A. Kopytenko, K. Hattori and M. Hayakawa (2002). Variations of phase velocity and gradient values of ULF geomagnetic disturbances connected with the Izu strong earthquakes, Nat. Hazards Earth Syst. Sci., 20, 1-5.

Johnston, M.J.S. (2002). Electromagnetic fields generated by Earthquakes, International Handbook of Earthquakes and Engineering Seismology, 81A, Elsevier Science Ltd.

Kangas, J., A. Guglielmi and O. Pokhotelov (1998). Morphology and physics of short period magnetic pulsations, Space Sci. Rev., 83, 435-512.

Kato, N., K. Yamamoto and T. Hirasawa (1994). Microfracture processes in the breakdown zone during dynamic shear rupture inferred from laboratory observation of near fault high frequency strong motion, Pageoph, 142, 713-734.

Kivelson, M.G., J. Etcheto and J.G. Trotignon (1984). Global compressional oscillations of the terrestrial magnetosphere: The evidence and a model, J. Geophys. Res., 89 (11), 9851-9856.

Kopytenko, Y.A., V.S. Ismaguilov, K. Hattori and M. Hayakawa (2002). Monitoring of the ULF electromagnetic disturbances at the station network before EQ in seismic zones of Izu and Chiba peninsulas, In: M. Hayakawa and O.A. Molchanov (eds.), Seismo Electromagnetics: Lithosphere-atmosphere-ionosphere coupling, 11-18, Terra Scientific, Tokyo.

Lanzerotti, L.J. (1978). Studies of geomagnetic pulsations, In: L.J. Lanzerotti and C.G. Park (eds.), Upper Atmosphere Research in Antarctica, 130, AGU, Washington D.C.

Lanzerotti, L.J., C.G. Maclennan and A.C. Fraser-Smith (1990). Background magnetic spectra: $\sim 10^{-5}$ to $\sim 10^{5}$ Hz, Geophys. Res. Lett., 17, 1593-1596.

McPherron, R.L. (1991). Physical Processes Producing Magnetospheric Substorms and Magnetic Storms, In: J. Jacobs (ed.), Geomagnetism, 593-739, Academic Press, London.

Meloni, A., P. Palangio and A.C. Fraser-Smith (1992). Some characteristics of the ELF/VLF radio noise measured near L'Aquila, Italy, IEEE T. Ant. Propag., 40 (2), 12-18.
Merzer, M., and S.L. Klemperer (1997). Modeling Lowfrequency Magnetic-field Precursors to the Loma Prieta Earthquake with a Precursory Increase in Fault-zone Conductivity, Pure Appl. Geophys., 150, 217-248.

Mochanov, O.A., and M. Hayakawa (1995). Generation of ULF electromagnetic emissions by microfracturing, Geophys. Res. Lett., 22, 3091-3094.

Palangio, P., C. Di Lorenzo, F. Masci and M. Di Persio (2007). The study of the electromagnetic anomalies linked with the Earth's crustal activity in the frequency band $[0.001 \mathrm{~Hz}-100 \mathrm{kHz}]$, Nat. Hazards Earth. Syst. Sci., 7, 507-511.

Palangio, P., A. Lozito, A. Meloni and C. Bianchi (2008). Electromagnetic Monitoring MEM Project, Quaderni di Geofisica, 53, INGV (in Italian).

Pulinets, S.A., N. Kotsarenko, L. Ciraolo and I.A. Pulinets (2007), Special case of ionospheric day-to-day variability associated with earthquake preparation, Adv. Space Res., 39, 970-977; doi:10.1016/j.asr.2006. 04.032.

Samson, J.C., and G. Rostoker (1972). Latitude-dependent characteristics of high latitude Pc4 and Pc5 micropulsations, J. Geophys. Res, 77, 6133.

Scholz, C.H. (1968). Microfracturing and the inelastic deformation of rock in compression, J. Geophys. Res., 73 (4), 1417-1432; doi:10.1029/JB073i004p01417.

Scoville, J., J. Heraud and F. Freund (2014). Pre-earthquake magnetic pulses, Nat. Hazards Earth Syst. Sci. Discuss., 2, 7367-7381; doi:10.5194/nhessd-2-73672014

Sentman, D.D. (1987). Magnetic polarization of Schumann resonances, Radio Sci., 22, 595-606.

Sentman, D.D., and B.J. Fraser (1991). Simultaneous observations of Schumann resonances in California and Australia: evidence for intensity modulation by the local height of the D-region, J. Geophys. Res., 96, 15973-15984.

Simpson, J.J., and A. Taflove (2005). Electrokinetic effect of the Loma Prieta earthquake calculated by an entire Earth FDTD solution of Maxwell's equations, Geophys. Res. Lett., 32; doi:10.1029/2005GL022601.

Stuart, W.D. (1974). Diffusionless dilatancy model for earthquake precursors, Geophys. Res. Lett., 1, 261264; doi:10.1029/GL001i006p00261.

Surkov, V.V., and M. Hayakawa (2008). Natural electromagnetic ULF noise due to fluctuations of ionospheric currents, J. Geophys. Res., 113, A11310; doi:10.1029/2008JA013196.

Surkov, V.V., and V.A. Pilipenko (2014). Estimate of ULF electromagnetic noise caused by a fluid flow during seismic or volcano activity, Nat. Hazards Earth Syst. Sci., Discuss., 2, 6475-6497. 
Teisseyre, R., and T. Ernst (2002). Electromagnetic radiation related to dislocation dynamics in a seismic preparation zone, Annals of Geophysics, 45 (2), 393-399.

Thomas, J.N., J.J. Love and M.J.S. Johnston (2009). On the reported magnetic precursor of the 1989 Loma Prieta earthquake, Phys. Earth Planet. Int., 173, 207215; doi:10.1016/j.pepi.2008.11.014.

Thomas, J.N., J.J. Love and M.J.S. Johnston and K. Yumoto (2009). On the reported magnetic precursor of the 1993 Guam earthquake, Geophys. Res. Lett., 36, L16301; doi:10.1029/2009GL039020.

Thomas, J.N., J.J. Love, A. Komjathy, O.P. Verkhoglyadova, M. Butala and N. Rivera (2012). On the reported ionospheric precursor of the 1999 Hector Mine, California earthquake, Geophys. Res. Lett., 39, L06302; doi:10.1029/2012GL051022.

Uyeda, S., T. Nagao and M. Kamogawa (2009). Shortterm earthquake prediction: current status of seismoelectromagnetics, Tectonophysics, 470, 205-213.

Wait, J.R. (1982). Geo-electromagnetism, Academic Press Inc., $265 \mathrm{pp}$.

Warwick, J.W., C. Stoker and T.R. Meyer (1982). Radio emission associated with rock fracture: possible application to the great Chilean earthquake of May 22, 1960, J. Geophys. Res., 87, 2851-2859.

Yumoto, K. (1988). External and internal sources of low-frequency MHD waves in the magnetosphere: A review, J. Geomag. Geoelectr., 40, 293-311.

Corresponding author: Cesidio Bianchi,

Istituto Nazionale di Geofisica e Vulcanologia, Rome, Italy;

email: cesidio.bianchi@ingv.it.

(C) 2015 by the Istituto Nazionale di Geofisica e Vulcanologia. All

rights reserved. 